\title{
PELATIHAN MENU SEHAT SEIMBANG UNTUK DIABETES DI DESA BINAAN KERAMBITAN
}

\author{
Made Kurnia Widiastuti Giri ${ }^{1}$, Arya Nugraha ${ }^{2}$, Adnyana Putra ${ }^{3}$, Ekanova Dharmapala ${ }^{4}$, \\ Komang Hendra Setiawan ${ }^{5}$ \\ 1,2,3,4,5 Prodi Kedokteran, FK Universitas Pendidikan Ganesha \\ e-mail: kurnia.widiastuti@undiksha.ac.id, arya.nugraha@undiksha.ac.id, \\ adnyanaputra@undiksha.ac.id, ekanova.dharmapala@undiksha.ac.id, \\ hendra.setiawan@undiksha.ac.id
}

\begin{abstract}
Abstrak
Upaya peningkatan kesehatan masyarakat melalui tindakan promotif dan preventif membutuhkan adanya perubahan perilaku hidup sehat di kalangan masyarakat desa yang bersifat mendasar dan fundamental. Program pengabdian kepada masyarakat ini berangkat dari potensi dan kebutuhan dari masyarakat Desa Kerambitan. Desa Kerambitan dipilih sebagai tempat pelaksanaan program pengabdian kepada masyarakat dikarenakan adanya beberapa data yaitu adanya 1) tingginya kebutuhan edukasi dan pendampingan holistik bagi lansia dengan penyakit diabetes ; 2) rendahnya pengetahuan dan keterampilan ibu rumah tangga dalam menyusun menu pencegahan penyakit degenerative seperti diabetes. Tujuan kegiatan ini adalah untuk memberikan solusi dari kedua permasalahan di kelompok sasaran. Hasil pendampingan menunjukkan peningkatan kognitif dan keterampilan melalui hasil pretest dan post test serta hasil penilaian ceklis keterampilan menyusun menu seimbang untuk pasien diabetes yang diberikan sebelum dan sesudah kegiatan. Kegiatan pendampingan di dua generasi ini telah meningkatkan pengetahuan dan keterampilan dari kedua kelompok sasaran dan menjadi cikal bakal pengembangan desa sehat di desa Kerambitan.
\end{abstract}

Kata kunci: promotif, sehat,diabetes

\begin{abstract}
Efforts to improve public health state through promotive and preventive actions required fundamental changes in healthy living behavior among rural communities. This community service program departs from the potential and needs of the people of Kerambitan Village. Kerambitan Village was chosen as the place for the implementation of the community service program due to several following datas: 1 ) the high need for holistic education and assistance for the elderly with diabetes; and 2) the lack of knowledge and skills of housewives in preparing menus for preventing degenerative diseases such as diabetes. The purpose of this activity is to provide solutions to the two problems in the target group. The results of the mentoring showed an increase in cognitive and skills through the results of the pretest and posttest as well as the results of the skill checklist for compiling a balanced menu for diabetic patients given before and after the activity. Mentoring activities in these two generations have increased the knowledge and skills of the two target groups and became the forerunner to the development of a healthy village in the village of Kerambitan.
\end{abstract}

Keywords: promotive, health, diabetes 


\section{PENDAHULUAN}

Pembangunan kesehatan di desa diarahkan pada pengutamaan upaya peningkatan pencegahan penyakit (preventif), dan peningkatan promosi kesehatan (promotif). Namun demikian, tidak dikesampingkan dalam upaya meningkatkan derajat kesehatan masyarakat dilakukan pengobatan penyakit (kuratif) dan pemulihan kesehatan (rehabilitatif) utamanya bagi penduduk miskin. Pembangunan kesehatan di desa harus dilakukan secara terpadu, terintegrasi dan berkesinambungan dengan mendayagunakan potensi sumber daya maupun layanan kesehatan yang tersedia di desa. Literasi kesehatan ini merupakan aktifitas masyarakat desa dalam membaca dan membelajari beragam informasi tentang kesehatan, menganalisis kondisi kesehatan di desa berdasarkan pengetahuan tentang kesehatan, dan mengubah pola hidup untuk menjadi lebih sehat sesuai dengan pengetahuan tentang kesehatan yang dipelajarinya. Dengan demikian, literasi kesehatan di desa mensyaratkan adanya kemudahan akses masyarakat desa pada informasi kesehatan. Semakin besar muatan informasi kesehatan yang diterima oleh masyarakat desa, maka akan lebih mudah bagi masyarakat desa untuk melakukan alih pengetahuan dan keterampilan tentang kesehatan yang beerdampak langsung pada peningkatan perilaku hidup sehat (Ardana, 2015; Soelistijo, 2015). Pembangunan bidang kesehatan di desa tidak terbatas pada urusan literasi dan informasi kesehatan. Lebih daripada itu urusan pembangunan di bidang kesehatan ini juga mencakup advokasi kebijakan pembangunan desa. Intinya, masyarakat desa harus berupaya dan berjuang mengakses sumber daya pembangunan di desa untuk memenuhi kepentingan diri dan kelompoknya terkait pemenuhan kebutuhan kesehatan (Nusadewiarti, 2020). Potensi Desa Kerambitan merupakan desa yang memiliki tiga generasi yaitu $\mathrm{X}, \mathrm{Y}$ dan $\mathrm{Z}$. Generasi $X$ dan $Y$ di desa pada program ini merupakan dua generasi yang bertatut erat karena lansia tinggal dengan anaknya (kelompok ibu) dan menu hariannya disediakan oleh kelompok ibu (anak ataupun menantunya). Kedua generasi ini harus diserasikan agar menjadi satu komunitas yang menjadikan Desa Kerambitan sebagai role model desa sehat di Bali. Oleh karena kegiatan pengabdian pada masyarakat Desa Binaan Sehat di Desa Kerambitan Kabupaten Tabanan ini sangat penting bagi tim pelaksana maupun mitra dea kerambitan.

Program pengabdian kepada masyarakat ini berangkat dari potensi dan kebutuhan dari masyarakat Desa Kerambitan. Desa Kerambitan dipilih sebagai tempat pelaksanaan program pengabdian kepada masyrakat dikarenakan adanya beberapa data yang mendukung desa ini menjadi prioritas dalam pemilihan tempat pelaksanaan program. Data yang diperoleh dari pemerintahan desa dan fasilitas kesehatan di wilayah setempat melalui observasi dan wawancara langsung menunjukkan beberapa hal sebagai berikut:

1. Tingginya kebutuhan edukasi dan pendampingan holistik bagi lansia. Jumlah kasus lansia dengan penyakit degenartif termasuk diabetes melitus cukup tinggi dimana ada kelompok prolanis di faskes puskesmas yang mengelola lebih dari 50 pasien dengan penyakit kronis yaitu penyakit diabetes.

2. Rendahnya pengetahuan dan keterampilan ibu rumah tangga dalam pencegahan penyakit degeneratif dari segi penyediaan makanan dengan menu seimbang untuk pasien diabetes dan mencegah keluarga dari konsumsi gula berlebih.

Kedua kelompok masyarakat tersebut dipaparkan oleh perangkat desa sebagai kelompok yang memiliki kebutuhan yang harus segera diberikan suatu program penyelesaian yang bersifat berkesinambungan. Kepala Puskesmas menambahkan jika dibandingkan dengan wilayah kerja Puskesmas lain di Kecamatan Kerambitan maka jumlah lansia Desa Kerambitan tergolong yang tertinggi demikian juga jumlah penyakit degeneratifnya. Kepala Puskesmas menambahkan bahwa belum ada satu program keluarga sehat dimana ibu rumah tangga mampu menerapkan pola hidup 
sehat dan menyiapkan menu yang tepat untuk anggota keluarga yang beresiko atau memiliki penyakit degeneratif. Dengan adanya dukungan dari perangkat desa dan penyedia layanan kesehatan serta kepakaran tim pelaksana maka program pengabdian masyarakat ini akan menjadi solusi bagi permasalahan yang ada di Desa Kerambitan terkait kesehatan.

Program desa binaan sehat ini mengacu pada program kementrian kesehatan yaitu program Indonesia sehat dengan pendekatan keluarga.

\section{METODE}

Model program pengabdian pada masyarakat ini yang dilaksanakan adalah pendampingan keluarga dalam dua generasi dengan menggunakan paket sehat keluarga yang terdiri dari buku menu sehat diabetes dan konsultasi pakar. Pendampingan pada kelompok sasaran dibagi menjadi dua dan berjalan secara paralel. Dua kelompok yang dimaksud adalah:

a. Kelompok Lansia (Generasi baby Boomers)

b. Kelompok Ibu PKK (Generasi Y)

Pendampingan akan dilaksanakan dengan metode pelatihan pengantar dan terbimbing, dengan teknik pemberian ceramah, demonstrasi, dan dilanjutkan dengan monitoring kegiatan. Evaluasi kegiatan dilaksanakan melalui pretest dan posttest. Terkait dengan penyakit diabetes pada lansia yang telah mendapatkan pengobatan, maka evalusi dilaksanakan dengan pengisian buku menu sehat diabetes sebagai catatan harian selama 1 bulan.

Program aksi pemberdayaan masyarakat yang menempatkan masyarakat secara aktif berpartisipasi dalam perencanaan, pelaksanaan, monitoring, dan evaluasi melalui proses pembelajaran dan pendampingan akan dapat meningkatan intensitas partisipasi, self-belonging, dan responsibility sehingga dapat menjamin dukungan material, finansial, dan pemikiran tepat sasaran dalam pemberdayaan masyarakat untuk mengantarkan masyarakat hidup lebih mandiri, aman, sejahtera, sehat dan harmonis.
Metode yang akan digunakan untuk pelaksanaan program kegiatan pengembangan desa binaan ini adalah metode SLA (Sustainable Livelihoods Approach). Pemberdayaan masyarakat dengan the Sustainable Livelihoods Approach (SLA) pada dasarnya upaya pelibatan (partisipasi) masyarakat untuk belajar dan beraktivitas secara berkelanjutan dengan cara unik mereka menjalani hidup dalam rangka meningkatkan kualitas hidup mereka.

\section{HASIL DAN PEMBAHASAN}

Diabetes Mellitus (DM) umumnya dibagi menjadi 2 tipe, yaitu diabetes melitus yang tergantung dengan insulin (DM tipe 1) dan diabetes melitus yang tidak tergantung dengan insulin (DM tipe 2) Gomes, 2019). Selain itu, terdapat jenis lain dari diabetes melitus yang tidak kalah pentingnya yaitu DM gestasional (terdiagnosis pada kehamilan trimester kedua atau ketiga), dan jenis diabetes tertentu karena penyebab lainnya, seperti sindrom diabetes monogenik (diabetes neonatal dan maturity-onset diabetes of the young (MODY), penyakit pankreas eksokrin (fibrosis kistik dan pankreatitis), obat-obatan, ataupun diabetes yang diinduksi oleh bahan kimia (glukokortikoid, pengobatan HIV / AIDS, atau transplantasi organ) (Care \& Suppl, 2019).

Kegiatan pelatihan ini dilaksanakan melalui tahap persiapan (observasi dan penentuan PIC serta pembagian timeline tugas ), Pelaksanaan dengan sesi pelatihan dan pendampingan serta evaluasi.

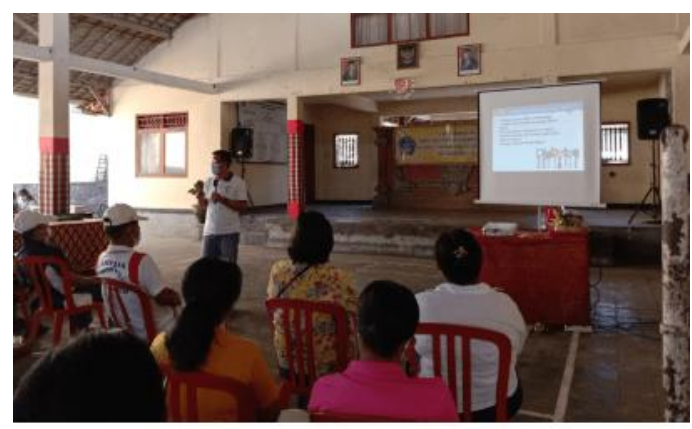

Gambar 1. Pelatihan Menu Sehat Seimbang Diabetes Oleh Pakar IImu Penyakit Dalam (Sumber: Dokumentasi Tim Pelaksana) 


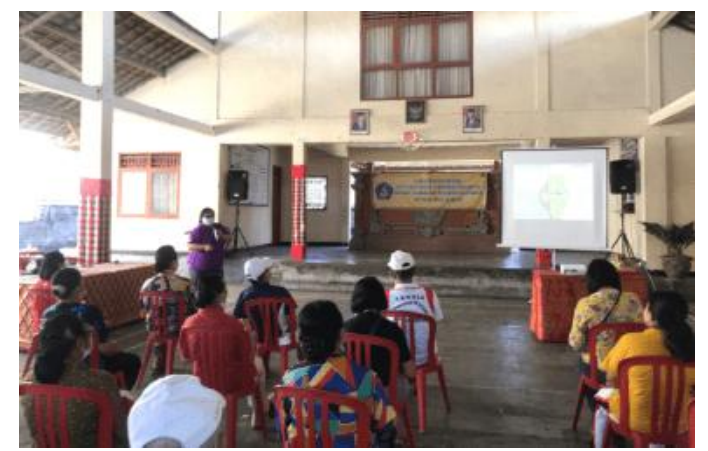

Gambar 2. Pelatihan Osteoartritis oleh Pakar Ortopedi.

(Sumber: Dokumentasi Tim Pelaksana)

Tujuan dari terselenggaranya pendampingan dan pelatihan ini adalah tumbuhnya pemahaman masyarakat dua generasi yaitu lansia dan ibu rumah tangga usia 30-45 tahun akan pentingnya saling menjaga kesehatan di lintas generasi. Kegiatan ini adalah pengabdian kepada masyarakata dalam skema desa binaan di desa kerambitan. Desa kerambitan dibina menjadi desa sehat dengan program sehat tiga generasi. Genarasi lansia yang mampu mengelola diabetes dan osteortritis. Ibu sebagai ibu rumah tangga yang mampu mengelola menu sehat diabetes. Penggunaan metode demonstrasi dalam pelatihan ini didasari oleh hasil penelitian yang menyatakan bahwa metode demonstrasi sangat sesuai dalam memberikan keterampilan proses kepada peserta dan dapat memberikan pengalaman belajar yang lebih kongkret (Nusadewiarti, 2020). Sebelum diberikan pelatihan, para peserta terlebih dahulu diberikan semacam pertanyaan-pertanyaan sederhana untuk mengetahui kemampuan awal mereka dalam pengelolaan diabetes, menu sehat Materi berupa apa dan bagaimana gejala dan tanda diabetes, komplikasi, dan menu untuk pasien diabetes. Diabetes melitus atau DM merupakan suatu penyakit gangguan metabolik yang ditandai dengan tingginya kadar glukosa dalam darah oleh karena terjadinya penurunan sekresi insulin oleh sel beta pankreas, gangguan resistensi insulin, ataupun keduanya (Of \& Mellitus, 2014; Rusdi, 2020). Menu menjadi hal yang penting diberikan karena seringkali pasien mengalami kondisi hipoglikemia. Suplai glukosa sangatlah penting pada otak, yang digunakan sebagai bahan bakar metabolisme dan support kognitif. Apabila terjadi penurunan kadar glukosa darah, maka akan terjadi disfungsi kognitif (Rusdi, 2020). Gejala-gejala yang termasuk ialah gangguan mental, mudah marah, bingung, kesulitan berbicara, ataksia, parestesia, sakit kepala, pingsan, dan akhirnya kejang, koma, dan bahkan kematian jika tidak diobati (Briscoe \& Davis, 2006).

Kegiatan pengabdian kemudian dilanjutkan dengan diskusi (sharing) yang berkaitan dengan materi yang sudah disampaikan sebelumnya dan diikuti dengan sesi demonstrasi dan praktek peserta dalam melakukan pemilihan bahan makanan sesuai perhitungan kalori menu harian diabetes. Kegiatan terakhir ini menjadi evaluasi untuk melihat peningkatan kemampuan pemilihan bahan makanan untuk menu harian sehat seimbang bagi pasien diabetes usia lansia dan juga pencegahan diabetes berupa makanan yang dianjurkna dan yang harus dibatasi konsumsinya dalam menu harian keluarga.

Motivasi para peserta dalam mengikuti pelatihan ini cukup tinggi yang terlihat dengan tingkat kehadiran $96 \%$ dari jumlah peserta yang ditargetkan sebelumnya. Materi pelatihan juga diberikan kepada setiap peserta dalam bentuk hardcopy agar jika mereka merasa perlu mencatat menu harian maka mereka bisa melakukannya sendiri dan melakukan konsultasi dengan pakar melalui meia online whatsapp. Peserta berlatih mempergunakan buku modul menu harian sehat seimbang diabetes sedangkan pengabdi mengarahkan mereka dan mengkoreksi apabila terdapat kesalahanLansia dan ibu rumah tangga cukup bersemangat dan berusaha mengikuti kegiatan pelatihan hingga akhir dan sanagt aktif dalam kegiatan diskusi dan demonstrasi. Dalam sesi diskusi terdapat beberapa peserta yang mengajukan pertanyaan berkaitan dengan diabetes. Berdasarkan hasil evaluasi di akhir kegiatan pelatihan, terlihat secara umum penguasaan tentang pengelolaan diabetes khususnya menu sehat seimbang. Oleh karena itu mereka sangat merasa terbantu dengana danya kontak person 
sebagai pendamping yang akan memberikan pendampingan untuk keberlanjutan program.

\section{KESIMPULAN}

Kegiatan pelatihan diikuti oleh 40 peserta yang merupakan 20 orang lansia dan 20 orang ibu rumah tangga yang merupakan anggota PKK desa Kerambitan. Hampir seluruh peserta pelatihan belum memiliki pengetahuan dan keterampilan terkait menu sehat seimbang diabetes, namun dilihat dari antusiasme selama pelatihan, mereka memiliki potensi untuk ditingkatkan kemampuannya dalam pengelolaan diabetes. Manfaat sangat dirasakan oleh masyarakat didesa Kerambitan dan menjadikan kebutuhan kana kegiatan terkait kesehatan dalam bentuk pembinaan desa sehat masih banyak dibutuhkan. . Aspek kesehatan lebih banyak diberikan melalui latihan praktis, disampaikan dengan contoh-contoh sederhana, sehingga peserta dapat menyadari pentingnya kemnadirian keluarga dalam mengelola kesehatan keluarganya.

\section{DAFTAR PUSTAKA}

Briscoe, V. J., \& Davis, S. N. (2006). Hypoglycemia in type 1 and type 2 diabetes: Physiology, pathophysiology, and management. Clinical Diabetes, 24(3), 115-121.

Care, D., \& Suppl, S. S. (2019). 2. Classification and diagnosis of diabetes: Standards of medical care in diabetesd2019. Diabetes Care, 42(January), S13-S28. https://doi.org/10.2337/dc19-S002

D, Y. T. P., \& Nusadewiarti, A. (2020). Penatalaksanaan Pasien Diabetes Melitus Tipe 2 dengan Neuropati dan Retinopati Diabetikum Melalui Pendekatan Kedokteran Keluarga Management of Type 2 Diabetes Melitus Patient with Diabetic Neuropathy and Retinopathy Through The Family Medicine Approach. Medula, 9(4), 631-638.

Gomes, M. B., Rathmann, W., Charbonnel,
B., Khunti, K., Kosiborod, M., Nicolucci, A., Pocock, S. J., Shestakova, M. V., Shimomura, I., Tang, F., Watada, H., Chen, H., Cid-Ruzafa, J., Fenici, P., Hammar, N., Surmont, F., \& Ji, L. (2019). Treatment of type 2 diabetes mellitus worldwide: Baseline patient characteristics in the global DISCOVER study. Diabetes Research and Clinical Practice, 151, 20-32. https://doi.org/10.1016/j.diabres.2019.0 3.024

Grace Y Irene , Kuswinarti, M. K. (2020). Understanding Patients with Type 2 Diabetes Mellitus Using Oral Antidiabetic Drugs Gambaran Penderita Diabetes Mellitus tipe 2 dengan Obat Antidiabetik Oral Grace Y Irene *, Kuswinarti **, Maya Kusumawati *** * Faculty of Medicine Padjadjaran University *. 2(5), 61-75.

I Wayan A.P, K. N. . (2015). Empat Pilar Penatalaksanaan Pasien Diabetes Mellitus Tipe 2. Majority, 4(9), 8-12.

Soelistijo, S. A., Lindarto, D., Decroli, E., Permana, H., Sucipto, K. W., Kusnadi, Y., Budiman, \& Ikhsan, R. (2019). Pedoman pengelolaan dan pencegahan diabetes melitus tipe 2 dewasa di Indonesia 2019. Perkumpulan Endokrinologi Indonesia, 1-117. https://pbperkeni.or.id/wpcontent/uploads/2020/07/PedomanPengelolaan-DM-Tipe-2-Dewasa-diIndonesia-eBook-PDF-1.pdf

Soelistijo, S., Novida, H., Rudijanto, A., Soewondo, P., Suastika, K., Manaf, A., Sanusi, H., Lindarto, D., Shahab, A., Pramono, B., Langi, Y., Purnamasari, D., \& Soetedjo, N. (2015). Konsesus Pengelolaan Dan Pencegahan Diabetes Melitus Tipe2 Di Indonesia 2015. In Perkeni.

Of, D., \& Mellitus, D. (2014). Diagnosis and classification of diabetes mellitus. Diabetes Care, 37(SUPPL.1), 81-90. https://doi.org/10.2337/dc14-S081

Rusdi, M. S. (2020). Journal Syifa Sciences And Clinical Research ( JSSCR ). 2(September),
83-90. 